\title{
Adverse Effects of Risperidone on Eye Movement Activity: A Comparison of Risperidone and Haloperidol in Antipsychotic-Naive Schizophrenic Patients
}

John A. Sweeney, Ph.D., Kenneth S. Bauer, B.S., Matcheri S. Keshavan, M.D., Gretchen L. Haas, Ph.D., Nina R. Schooler, Ph.D., and Patricia D. Kroboth, Ph.D.

Risperidone is a novel and clinically effective atypical antipsychotic medication with a unique biochemical profile. To contrast the neurophysiological effects of this new medication with those of a typical antipsychotic medication, we performed quantitative measurements of saccadic eye movements in a series of antipsychotic-naive schizophrenic patients treated with either risperidone or haloperidol. Patients were tested before and after 1 month of treatment, and a matched group of healthy subjects was tested twice over a similar time interval. Risperidone, but not

KEY WORDS: Risperidone; Haloperidol; Saccades; Eye movements; Side effects

Risperidone is a novel benzisoxazole derivative with demonstrated clinical efficacy as an antipsychotic agent in the treatment of schizophrenia (Chouinard et al. 1993; Marder and Meibach 1994; Schooler 1994). Receptor binding studies in rodents and human PET studies have demonstrated that risperidone is a potent $5-\mathrm{HA}_{2 \mathrm{~A}}$ antagonist at low dosages and a potent $\mathrm{D}_{2}$ antagonist at

From the Departments of Psychiatry (JAS, MSK, GLH, NRS) and Neurology (JAS), Neurobehavioral Studies Program, University of Pittsburgh School of Medicine; and the Department of Pharmacy and Therapeutics (KSB, PDK), University of Pittsburgh School of Pharmacy, Pittsburgh, PA.

Address correspondence to: John A. Sweeney, Ph.D., Western Psychiatric Institute and Clinic, $3811 \mathrm{O}^{\prime}$ Hara Street, Pittsburgh, PA 15213.

Received March 18, 1996; revised August 15, 1996; accepted August 19, 1996 haloperidol, was associated with prolonged latency and decreased peak velocity and accuracy of saccadic eye movements that was detectable 4 weeks after treatment initiation. The adverse effects of risperidone may be due to the lack of development of acute tolerance to its powerful serotonergic (5-HT $2 A$ ) antagonism, which could be responsible for the disruption of brainstem physiology in regions controlling saccadic eye movements. (C) 1997 American College of Neuropsychopharmacology [Neuropsychopharmacology 16:217-228, 1997]

higher doses (Nyberg et al. 1993; Sumiyoshi et al. 1994). Its affinity is approximately 20 times higher for $5-\mathrm{HT}_{2 \mathrm{~A}}$ than $\mathrm{D}_{2}$ receptors, and among serotonergic receptor subtypes the effects are highly selective for $5-\mathrm{HT}_{2 \mathrm{~A}}$ receptors (Janssen and Awouters 1994; Leysen et al. 1994). Risperidone possesses an affinity for $D_{2}$ receptors that is approximately two to three times less than haloperidol and a lower affinity at $\mathrm{H}_{1}$ and muscarinic receptors than the atypical antipsychotic clozapine (Leysen et al. 1994).

Clinical trials suggest that risperidone may have therapeutic advantages relative to the typical antipsychotics haloperidol (Borison et al. 1992; Chouinard and Arnott 1993; Marder and Meibach 1994; Owens 1994; Schooler 1994) and perphenazine (Hoyberg et al. 1993), including greater efficacy in reducing negative symptoms, less frequent extrapyramidal side effects, and perhaps a faster onset of action. Clinically significant hematological and cardiovascular side effects are uncommon during treatment with risperidone (Mesotten 
et al. 1989). Sedation has been reported as an adverse effect in some studies (Hoyberg et al. 1993; Heinrich et al. 1994), as has been described for the atypical antipsychotic clozapine (Lieberman and Safferman 1992; Centorrino et al. 1994). To date, clinical studies of the efficacy and adverse effects of risperidone have been conducted almost exclusively with chronically ill schizophrenic patients and have utilized clinician- or observer-rated assessment of adverse effects. One quantitative EEG study reported that risperidone, in contrast to haloperidol, induces a widespread change in interhemispheric power asymmetry. These changes were seen in both the beta and theta bands and were attributed to serotonergic mechanisms (Czobor and Valavka 1993).

Previous research has demonstrated dose-related changes in saccadic eye movements in response to a variety of CNS-active medications and drugs of abuse. Saccades are brief rapid eye movements that shift the focus of gaze from one point to another in the visual field. Some drugs appear to disrupt all aspects of saccadic eye movements, including their latency, accuracy and peak velocity. Drugs that reduce alertness or have sedative effects, such as benzodiazepines (Bittencourt et al. 1981; Jurgens et al. 1981; Hommer et al. 1986; RoyByrne et al. 1993), barbiturates (Schalen et al. 1988), clonidine (Glue et al. 1991), nitrous oxide (Gao et al. 1991), the calcium channel blocker flunarizine (Tedeschi et al. 1992), methadone (Rothenberg et al. 1980), and alcohol (Baloh et al. 1979; Katoh 1988), all distort the latency, peak velocity, and accuracy of saccades. The anticonvulsant carbamazepine has been shown to disrupt saccade dynamics at lower doses than those required to cause clinically detectable sedation (Tedeschi et al. 1989).

Other drugs appear to affect only the initiation of saccades, but not the actual dynamics of these eye movements (such as their peak velocity and duration). Scopolamine reduces nystagmus after vestibular challenge (Pyykko et al. 1985), reflecting cholinergic modulation of the vestibular nuclei. The NMDA receptor antagonist ketamine disrupts gaze maintenance but not the dynamics of saccades (e.g., peak velocity and accuracy) (Godaux et al. 1990). Parkinsonism associated with 1-methyl-4-phenyl-1,2,3,6-tetrahydropyridine (MPTP) is most consistently associated with prolonged saccade latency rather than altered saccade dynamics, although disturbances in saccade dynamics are seen in some cases (Brooks et al. 1986; Schultz et al. 1989). Disturbances in saccade dynamics are most clearly related to altered function in the superior colliculus and its target projections in the brainstem and in the cerebellum (Keller 1989), as these regions code the dynamics of saccadic eye movements (Waitzman et al. 1991).

Oculomotor measurements offer several significant advantages relative to self- or observer-ratings of drug effect. First, the measurements are objective and quantitative, and are not dependent on the accuracy of patient self-report or clinician ratings. Second, although subjects can voluntarily control the initiation and target for saccades, the dynamics of these eye movements are not under voluntary control and are therefore minimally influenced by intentional motivational factors. Third, saccades are known to be highly sensitive to variations in fatigue and alertness (Becker 1989). Fourth, the brain systems that control eye movements are relatively well understood both anatomically and biochemically, based on behavioral and single-cell electrophysiological studies in alert behaving monkeys (Fischer 1987; Sawaguchi et al. 1989; Sawaguchi and Goldman-Rakic 1991; Goldman-Rakic et al. 1992) and human functional neuroimaging studies (Fox et al. 1985; Sweeney et al. 1996), making this an ideal system for studying pharmacological effects on brain systems.

Disturbances of pursuit eye movements are well established in schizophrenia, including studies establishing the presence of reduced pursuit gain in never-treated patients (Holzman et al. 1974; Sweeney et al. 1994a; Friedman et al. 1995). The pursuit system does not appear to be affected by typical neuroleptic medications, at least not after 1 month of treatment (Friedman et al. 1991; Sweeney et al. 1994b). The effects of the atypical antipsychotic clozapine on pursuit eye movements remain controversial (Friedman et al. 1991; Litman et al. 1994).

In contrast to the consistent finding of pursuit disturbances in schizophrenia, reflexive saccadic eye movements have not been found to be impaired in most studies of schizophrenic patients (Fukushima et al. 1990; Abel et al. 1992; Clementz et al. 1994). Some studies have reported saccade abnormalities (Cegalis et al. 1982; Moser et al. 1990), but these effects were subtle and observed in chronically ill patients taking typical antipsychotic medications. Because of the motor system disturbances sometimes associated with neuroleptic treatment and reports indicating that acute doses of both remoxipride and chlorpromazine impair saccades in healthy subjects (King et al. 1995), studies of untreated patients are needed to determine whether there are disturbances in brain regions subserving saccadic eye movements in schizophrenia. At present, fewer data are available regarding the integrity of saccadic eye movements in treatment-naive schizophrenic patients or about the effects of typical or atypical antipsychotic medications on saccadic eye movements in the clinical setting. In the present study, we compared the effects of risperidone and haloperidol on several quantitative indices of saccadic eye movement activity in antipsychotic-naive first-episode schizophrenic patients.

\section{METHODS}

The study was conducted as part of the University of Pittsburgh First Episode Project, an ongoing prospec- 
tive study of the early course of schizophrenia. The patient sample was comprised of 20 antipsychotic-naive patients with a DSM-III-R diagnosis of schizophrenia $(n=15)$ or schizoaffective $(n=5)$ disorder. Diagnoses were based on Structured Clinical Interview for DSMIII-R (SCID) diagnoses (Spitzer et al. 1987) and all other available information that were reviewed at a consensus diagnosis meeting by senior investigators and clinical staff. Follow-up evaluations were conducted to confirm diagnoses. Matched healthy comparison subjects were recruited ( $n=10$ ) from the surrounding community and verified to have no Axis I disorder by SCID interview. The healthy comparison group was selected to match the patient sample on age, sex, and parental socioeconomic status. All subjects met the following criteria: (1) age between 18 and 45 years; (2) no known systemic or neurological illness; (3) no prior treatment with electroconvulsive therapy (ECT); (4) no history of head trauma with loss of consciousness; (5) no lifetime history of substance dependence or of substance abuse in the 2 months preceding hospitalization; (6) no anticonvulsant or other benzodiazepines for 1 month; and (7) no coffee, tea, or cigarettes for 1 hour before eye movement testing. Patient reports of prior treatment history were confirmed by family members and treating physicians. Table 1 summarizes the demographic and clinical information for the three subject groups (risperidone, haloperidol, and healthy comparison; $n=10$ in each group). There were no significant group differences in age $(F=0.44, \mathrm{df}=2,27, \mathrm{NS})$, sex ratio $\left(\chi^{2}=2.39, \mathrm{df}=2\right.$,
NS), or IQ as assessed using the Ammon's Quick Test (Ammons and Ammons 1962) $(F=1.99, \mathrm{df}=2,27, \mathrm{NS})$.

Patients were administered a battery of psychopathology rating instruments at the time of each eye movement testing by clinicians having no knowledge of findings from eye movement studies. The battery included the Brief Psychiatric Rating Scale (BPRS; Overall and Gorham 1962) and the Schedules for the Assessment of Positive (SAPS; Andreasen 1984a) and Negative (Andreasen 1984b) Symptoms. At the time of the first eye movement testing, there were no significant differences between the two schizophrenic patient groups on any clinical measure (Table 1).

The first eye movement testing was conducted within 7 days prior to treatment initiation. Patients were retested after they had taken antipsychotic medication for approximately 4 weeks with the last 7 days on a stable dose, and healthy comparison subjects were retested after a similar time interval. The first series of 10 studyeligible consenting patients admitted for inpatient care to the Western Psychiatric Institute and Clinic were treated with haloperidol. Shortly after risperidone received FDA approval for the treatment of schizophrenia in December 1993, we began to treat the next series of 10 study-eligible patients with risperidone. Both medications were administered at relatively low doses to minimize adverse side effects, and because low-dose treatment is clinically effective in the treatment of many schizophrenic patients early in the course of illness (Van Putten et al. 1990; McEvoy et al. 1991). Eight of the

Table 1. Demographic and Clinical Characteristics of Schizophrenic Patients Treated with Risperidone or Haloperidol with Healthy Comparison Subjects

\begin{tabular}{|c|c|c|c|}
\hline & $\begin{array}{l}\text { Haloperidol-Treated } \\
\text { Patients }\end{array}$ & $\begin{array}{c}\text { Risperidone-Treated } \\
\text { Patients }\end{array}$ & $\begin{array}{c}\text { Healthy Comparison } \\
\text { Subjects }\end{array}$ \\
\hline Age & $24.5 \pm 9.3$ & $28.2 \pm 9.9$ & $25.5 \pm 8.0$ \\
\hline Gender $(\mathrm{M} / \mathrm{F})$ & $6 / 4$ & $9 / 1$ & $7 / 3$ \\
\hline Laterality ${ }^{a}$ & $9.3 \pm 3.1$ & $8.2 \pm 6.5$ & $9.7 \pm 2.7$ \\
\hline IQ & $99.7 \pm 15.3$ & $94.8 \pm 10.2$ & $106.9 \pm 14.9$ \\
\hline \multicolumn{4}{|l|}{ SAPS } \\
\hline Pretreatment & $8.6 \pm 3.9$ & $8.6 \pm 4.3$ & \\
\hline Posttreatment & $4.3 \pm 2.7^{* *}$ & $1.1 \pm 1.7^{* * *}$ & \\
\hline \multicolumn{4}{|l|}{ SANS } \\
\hline Pretreatment & $10.9 \pm 1.7$ & $11.7 \pm 3.6$ & \\
\hline Posttreatment & $8.8 \pm 2.1^{*}$ & $10.0 \pm 1.7$ & \\
\hline \multicolumn{4}{|l|}{ BPRS } \\
\hline · Pretreatment & $49.1 \pm 9.1$ & $49.4 \pm 12.7$ & \\
\hline Posttreatment & $36.8 \pm 9.0^{* *}$ & $30.2 \pm 5.5^{* * *}$ & \\
\hline Treatment duration (days) & $31.4 \pm 7.1$ & $30.5 \pm 5.9$ & \\
\hline Antipsychotic dose & $2.9 \pm 1.3$ & $4.2 \pm 2.3$ & \\
\hline Benztropine & $\begin{array}{c}1.7 \pm 1.2 \\
(n=8)\end{array}$ & $\begin{array}{c}1.0 \\
(n=1)\end{array}$ & \\
\hline
\end{tabular}


patients receiving haloperidol and one risperidonetreated patient also were treated with the anticholinergic medication benztropine.

\section{Saccadic Eye Movement Task}

Tasks were designed to elicit "reflexive" saccades to temporally and spatially unpredictable targets. These tasks are simple and straightforward; subjects were instructed to look quickly to visual targets wherever they appeared. EOG recordings were obtained (Grass Neurodata 12 Acquisition System, Astro-Med, Inc., West Warwick, RI) to assess visuomotor functions across a large range of the horizontal visual field. Trials began with a center fixation target that remained illuminated for 1.5 to $2.5 \mathrm{~s}$ (average $2.0 \mathrm{~s}$ ) before peripheral targets were presented to the left or right in the horizontal plane. Peripheral targets (target steps) were presented for $1.5 \mathrm{~s}$ at \pm 10 , 20 , or 30 degrees from center fixation. A total of 54 trials were presented. Targets were presented on a circular arc $1 \mathrm{~m}$ from subjects using individually addressable light-emitting diodes that subtended approximately 0.2 degrees of visual angle. Blinks were monitored using electrodes placed above and below the left eye. Data were digitized on-line at $500 \mathrm{~Hz}$ (Model DI-210 14-bit A/D converter, DATAQ Instruments, Akron, $\mathrm{OH}$ ).

Subjects were tested alone in a completely dark room to prevent distraction from extraneous information that can influence eye movements. A chin rest, with forehead and occipital restraints and a head strap, was used to maintain head stability. Instructions were given by a technician via intercom from an adjacent room. The technician monitored eye movements during task performance to provide instructions and realerting commands when necessary. When the central fixation point was presented at the beginning of each trial, a brief tone sounded behind the central fixation light to help subjects quickly refixate the central fixation cue (Konrad et al. 1989).

\section{Eye Movement Analysis}

Eye movement recordings were analyzed off-line using custom software written in this laboratory. Before any processing of the eye movement data took place, the data were smoothed with a finite-impulse response filter, a low-pass filter with a passband of 0 to $16 \mathrm{~Hz}$, a smooth transition band of 16 to $70 \mathrm{~Hz}$, and a stop band for frequencies $70 \mathrm{~Hz}$ and up. The filter was chosen empirically to reduce noise artifacts with a minimum of signal distortion.

Eye movement recordings from each trial were presented graphically to a technician for analysis. Eye position recordings were calibrated (i.e., converted from raw voltage data to eye movement in degrees of visual angle) for each trial independently using data from the time subjects fixated the central cue and the peripheral target. This "within-trial" calibration was performed to minimize artifacts resulting from drift in DC-EOG signals that can occur over the course of a study. Saccades were identified as beginning when eye velocity rose above 30 degrees/s and continuing until eye velocity returned below that level. The latency, peak velocity, and accuracy of the primary saccade on each trial were recorded.

The technician reviewed the results of algorithmbased analyses on a trial-by-trial basis and made modifications or deleted trials when an artifact occurred that was not detected by software. If a blink began between $100 \mathrm{~ms}$ before presentation of a peripheral target and

Table 2. Peak Velocity of Saccades (in degrees $/ s \pm$ SD) to Target-Steps of $+/-10,20$, and 30 Degrees from Central Fixation in Antipsychotic-Naive Schizophrenic Patients before and after 1 Month of Treatment with Haloperidol or Risperidone and in Healthy Comparison Subjects

\begin{tabular}{lccc}
\hline & Baseline & Second Testing & Change from Baseline \\
\hline $\begin{array}{l}\text { 10-Degree target steps } \\
\quad \text { Haloperidol }\end{array}$ & $317 \pm 42$ & $298 \pm 63$ & $-18 \pm 42$ \\
$\quad \begin{array}{l}\text { Risperidone } \\
\text { Control }\end{array}$ & $321 \pm 39$ & $280 \pm 46$ & $41 \pm 20^{* * *}$ \\
$\begin{array}{l}\text { 20-Degree target steps } \\
\text { Haloperidol }\end{array}$ & $296 \pm 37$ & $288 \pm 37$ & $-8 \pm 22$ \\
$\quad$ Risperidone & $422 \pm 73$ & $396 \pm 81$ & $-26 \pm 58$ \\
$\quad$ Control & $444 \pm 65$ & $389 \pm 83$ & $-54 \pm 33^{* * *}$ \\
30-Degree target steps & $418 \pm 38$ & $411 \pm 50$ & $-7 \pm 33$ \\
$\quad$ Haloperidol & $462 \pm 70$ & $423 \pm 89$ & $-38 \pm 66$ \\
Risperidone & $512 \pm 87$ & $416 \pm 97$ & $-96 \pm 60^{* * *}$ \\
Control & $440 \pm 46$ & $445 \pm 53$ & $5 \pm 52$ \\
\hline
\end{tabular}

Data presented are mean \pm standard deviation. ${ }^{* * *} p<.001$ from paired $t$-tests comparing pre- and posttreatment scores. 
the end of the primary saccade, or if a saccade occurred within $100 \mathrm{~ms}$ before and $70 \mathrm{~ms}$ after peripheral target presentation, the trial was excluded from analyses. Data from the right eye were scored unless this was precluded by recording artifact (i.e., signal clipping, or considerably greater bioelectric noise than in the left eye recording).

\section{Statistical Analysis}

The primary data analyses involved repeated-measures analyses of variance (ANOVAs) performed to assess subject group and time of testing effects. Because there were no significant laterality effects on any eye movement parameter, data from leftward and rightward saccades were pooled for all analyses. Paired $t$-tests contrasting saccades at the first and second testings were used to clarify treatment effects. Exploratory correlational analyses were performed to assess the association between performance on eye movement tasks and clinical symptom ratings, medication dose, and demographic variables.

\section{RESULTS}

\section{Comparisons of Patients and Healthy Comparison Subjects at Initial Testing}

The integrity of visually guided saccadic eye movements in the schizophrenic patients prior to treatment was assessed by comparing the baseline performance of all patients with that of the healthy comparison subjects. There were no significant differences between the healthy comparison subjects and the schizophrenic patients in the peak velocity ( $F=1.83, \mathrm{df}=1,28, \mathrm{NS})$, la- tency $(F=1.24, \mathrm{df}=1,28, \mathrm{NS})$, or accuracy $(F=3.71, \mathrm{df}=$ $1,28, N S)$ of saccades at the initial testing session when patients were untreated. Similar analyses comparing the pretreatment performance of the haloperidol- and risperidone-treated schizophrenic patients also failed to identify any significant differences in performance prior to the initiation of treatment.

\section{Clinical Treatment Effects}

Patients demonstrated a significant clinical improvement after 4 weeks of treatment with haloperidol and risperidone, as indicated in Table 1. This is reflected in the significantly reduced symptom ratings at the time of the second testing demonstrated using repeated measures analyses of variance: BPRS $(F=34.65, \mathrm{df}=1,18$, $p<.001)$, SAPS $(F=41.83, \mathrm{df}=1,18, p<.001)$, and SANS $(F=9.77, \mathrm{df}=1,18, p<.01)$. There were no significant differences in the magnitude of clinical change following treatment with risperidone or haloperidol on any of these measures (all $p^{\prime} s>.10$ ).

\section{Medication Effects on Eye Movements}

Peak velocity, latency, and accuracy of saccades from the two testing sessions are presented in Tables 2,3, and 4. Figures 1 and 2 show data from individual subjects for peak velocity and latency of saccades, respectively, in response to target displacements of 30 degrees of visual angle from center fixation. Differential changes between the first and second testing session were observed in the peak velocity $(F=5.87, \mathrm{df}=2,27, p<.01)$, latency $(F=4.21, \mathrm{df}=2,27, p<.03)$, and spatial error $(F=4.75, \mathrm{df}=2,27, p<.02)$ of saccades in the three subject groups. This differential effect was greater for

Table 3. Mean Latency ( $\mathrm{ms} \pm \mathrm{SD}$ ) to Initiate Saccades to Target-Steps of $+/-10,20$, and 30 Degrees from Central Fixation in Antipsychotic-Naive Schizophrenic Patients before and after 1 Month of Treatment with Haloperidol or Risperidone and in Healthy Comparison Subjects

\begin{tabular}{lccc}
\hline & Baseline & Second Testing & Change from Baseline \\
\hline $\begin{array}{l}\text { 10-Degree target steps } \\
\quad \text { Haloperidol }\end{array}$ & $179 \pm 29$ & $183 \pm 26$ & $3 \pm 16$ \\
$\quad$ Risperidone & $205 \pm 37$ & $221 \pm 55$ & $16 \pm 31$ \\
$\quad$ Control & $215 \pm 27$ & $219 \pm 41$ & $4 \pm 24$ \\
$\begin{array}{l}\text { 20-Degree target steps } \\
\quad \text { Haloperidol }\end{array}$ & $196 \pm 35$ & $199 \pm 21$ & $3 \pm 27$ \\
$\quad$ Risperidone & $221 \pm 40$ & $251 \pm 39$ & $30 \pm 26^{* *}$ \\
$\quad$ Control & $224 \pm 29$ & $227 \pm 35$ & $3 \pm 21$ \\
$\begin{array}{l}\text { 30-Degree target steps } \\
\quad \text { Haloperidol }\end{array}$ & $221 \pm 47$ & $214 \pm 32$ & $-7 \pm 45$ \\
$\quad$ Risperidone & $258 \pm 44$ & $289 \pm 58$ & $31 \pm 26^{* *}$ \\
$\quad$ Control & $246 \pm 24$ & $244 \pm 32$ & $-2 \pm 16$ \\
\hline
\end{tabular}

Data presented are mean \pm standard deviation. ${ }^{* *} p<.01$ from paired $t$-tests comparing pre- and posttreatment scores. 
Table 4. Mean Error of Saccades (in Degrees of Visual Angle \pm SD) to Target-Steps of $+/-$ 10, 20, and 30 Degrees from Central Fixation in Antipsychotic-Naive Schizophrenic Patients before and after 1 Month of Treatment with Haloperidol or Risperidone and in Healthy Comparison Subjects

\begin{tabular}{lccc}
\hline & Baseline & Second Testing & Change from Baseline \\
\hline $\begin{array}{l}\text { 10-Degree target steps } \\
\quad \text { Haloperidol }\end{array}$ & $-0.53 \pm 0.55$ & $-0.83 \pm 1.10$ & \\
$\quad$ Risperidone & $-0.34 \pm 0.32$ & $-0.70 \pm 0.54$ & $.31 \pm .76$ \\
$\quad$ Control & $-0.39 \pm 0.61$ & $-0.52 \pm 0.77$ & $.36 \pm .32^{* *}$ \\
$\begin{array}{l}\text { 20-Degree target steps } \\
\text { Haloperidol }\end{array}$ & $-2.07 \pm 1.05$ & $-1.79 \pm 0.97$ & $.13 \pm .33$ \\
Risperidone & $-1.25 \pm 0.83$ & $-2.01 \pm 1.080$ & $-0.28 \pm 1.04$ \\
$\quad$ Control & $-.98 \pm 0.75$ & $-0.98 \pm 0.70$ & $.76 \pm .75^{*}$ \\
30-Degree target steps & $-3.31 \pm 2.27$ & $-2.49 \pm 1.53$ & $0.0 \pm .53$ \\
$\quad$ Haloperidol & $-1.59 \pm 1.05$ & $-2.74 \pm 1.85$ & $-0.82 \pm 2.11$ \\
Risperidone & $-1.17 \pm 0.85$ & $-1.09 \pm 0.33$ & $1.14 \pm 1.83$ \\
$\quad$ Control & & & $-.08 \pm .61$ \\
\hline
\end{tabular}

Data presented are mean $=$ standard deviation. ${ }^{*} p<.05 ;{ }^{* *} p<.01$ from paired $t$-tests comparing pre- and posttreatment scores

the peak velocity of larger saccades $(F=3.90, \mathrm{df}=4,54$, $p<.01)$, but the magnitude of group differences in saccade latency and accuracy did not differ significantly in relation to the amplitude of the target displacement.

In a series of paired $t$-tests comparing performance from the first and second testings on saccade parameters where significant effects had been demonstrated in repeated-measures ANOVAs, there were no significant changes in any dimension of saccadic eye movement activity for the healthy comparison subjects or the haloperidol-treated patients. In contrast, the risperidonetreated patients showed a deterioration in the dynamics of saccadic eye movements after treatment. Significant increases in saccade latency were evident in response to both the 20- and 30-degree target steps, and increases in saccade error were evident in response to both 10- and 20-degree target steps. Significant decreases in peak saccade velocity were evident in saccades to all three amplitudes of the target steps. To verify that the reduced peak saccade velocity in the risperidone-treated patients was not accounted for by a reduction in saccade amplitude (smaller saccades have lower velocity), we computed the ratio of saccade velocity over saccade amplitude for each saccade. Analyses of these "amplitude-corrected" velocity indices revealed significant reductions in saccade velocity to both 20-degree $(t=3.00$, $\mathrm{df}=9, p<.02)$ and 30-degree $(t=4.04, \mathrm{df}=9, p<.003)$ target steps, but reductions in saccade velocity for saccades to the 10-degree step were no longer significant $(t=2.11, \mathrm{df}=9, p<.07)$. These analyses indicate that the reduced peak saccade velocity in the risperidonetreated patients represents a true reduction in peak saccade velocity [i.e., not a velocity reduction resulting merely from smaller amplitude (hypometric) saccades]. The magnitude of drug effects was not significantly cor- related with the oral dosage of antipsychotic medication or with changes on clinical ratings of symptom severity.

\section{DISCUSSION}

Treatment of antipsychotic-naive schizophrenic patients with risperidone led to significant clinical benefit, but also to adverse effects on saccadic eye movements that were evident after 4 weeks of treatment. These adverse effects were evident in the latency, peak velocity, and spatial error of visually guided "reflexive" saccades and suggest a treatment-related perturbation of brainstem physiology in regions that subserve saccadic eye movements.

In previous studies of the pharmacological effects of other CNS-active medications on saccadic eye movements, particularly benzodiazepines, acute tolerance to drug-induced effects on saccades develops quickly (on the order of hours; Kroboth et al. 1995). The effects of risperidone appear to be quite different. After 4 weeks of treatment, significant residual adverse drug effects were evident, which indicates, at the least, a very slow development of tolerance.

\section{Saccades in Schizophrenia}

There have been many demonstrations of abnormal pursuit eye movements in schizophrenia (Clementz and Sweeney 1990; Levy et al. 1994), but saccadic eye movements have been much less extensively investigated. To our knowledge, this is the first study to assess comprehensively multiple aspects of saccadic eye movements in a cohort of treatment-naive first-episode schizo- 


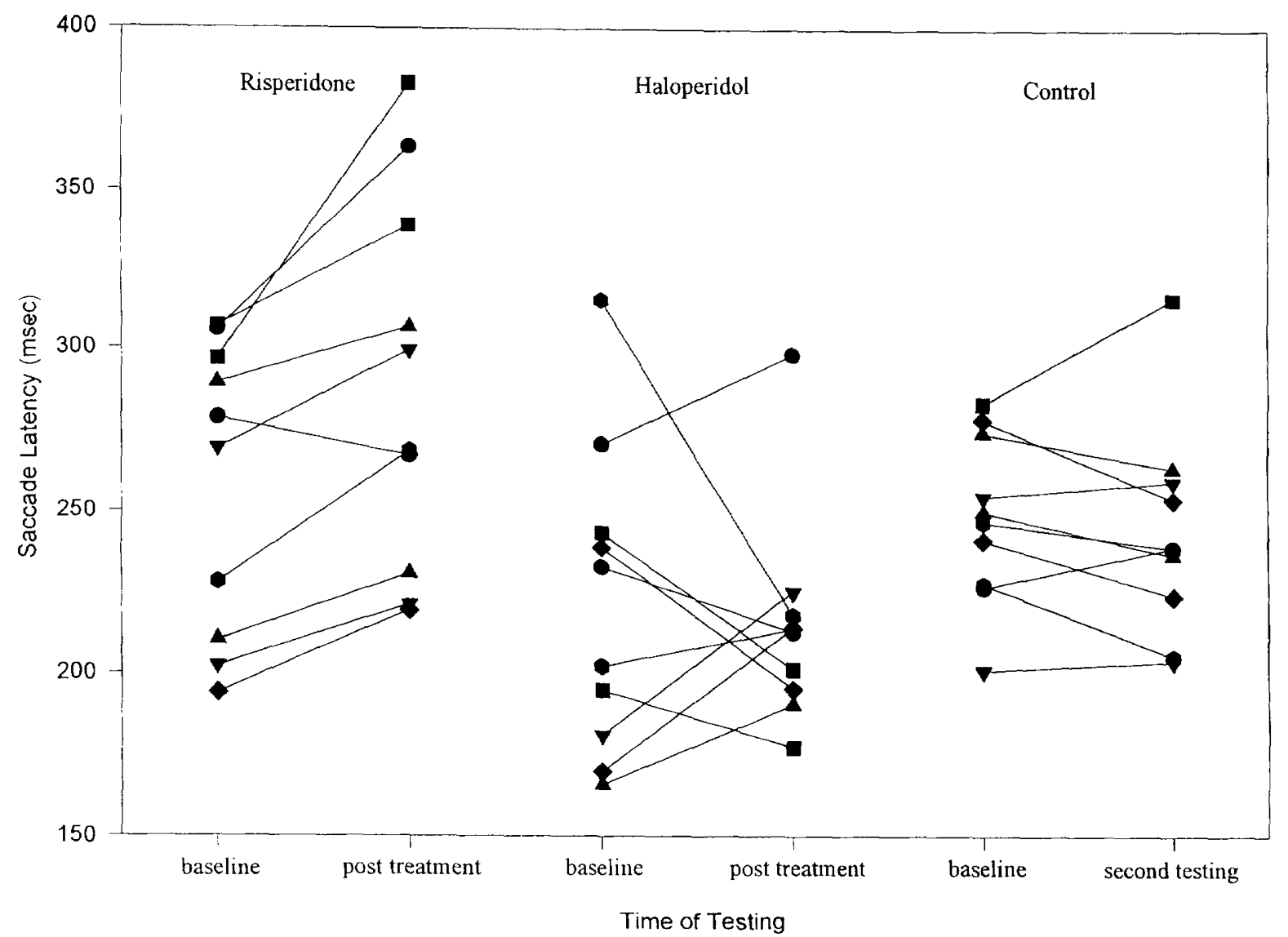

Figure 1. Individual subject data for average latency of saccadic eye movements to target-steps of \pm 30 degrees of visual angle from central fixation in antipsychotic-naive schizophrenic patients before and after one month of treatment with haloperidol or risperidone, and in healthy comparison subjects.

phrenic patients and to follow them over the early course of treatment with antipsychotic agents.

We did not identify any abnormalities in reflexive visually guided saccadic eye movements in these treatment-naive schizophrenic patients prior to treatment initiation. This observation is similar to the findings of most previous studies of schizophrenic patients, even though patients in those studies were almost always taking typical antipsychotic medications at the time they were studied (Mather and Putchat 1982; Yee et al. 1987; Fukushima et al. 1990; Clementz et al. 1994; Crawford et al. 1995b). However, there have been reports of saccade disturbances in schizophrenic patients. A subtle, but significant, increase in saccade error (dysmetria) has been reported in some studies (Cegalis et al. 1982; Mather and Putchat 1982; Moser et al. 1990; Crawford et al. 1995b), an abnormality that is pronounced in patients with tardive dyskinesia (Oepen et al. 1990). One study has reported a pattern of normal latency, but hypometric saccades, in schizophrenic patients who had been untreated for at least 6 months (Crawford et al. 1995a). An increased latency of visually guided saccades also has been reported in some studies of schizophrenic patients (Yee et al. 1987), and one group has shown this to be particularly pronounced in chronically ill patients with prominent negative symptoms (Mackert and Flechtner 1989). On the basis of the results of the present study, which indicate intact reflexive saccadic eye movements in schizophrenic patients prior to treatment initiation, previous reports of saccade abnormalities might represent adverse medication effects or pathophysiological changes associated with the course of illness.

\section{Treatment Effects on Saccades}

The results of the present study indicate significantly reduced peak velocity and accuracy of saccades and increased saccade latency in schizophrenic patients treated with relatively low doses of risperidone for approximately 1 month. Patients treated with haloperidol did not demonstrate these effects. The reduced peak velocity of saccades in risperidone-treated patients suggests a disturbance in brainstem physiology, because it implies a perturbation at the level of pontine burst cell input to oculomotor nuclei. The reduced saccade accuracy suggests a disturbance intrinsic to the brainstem or involving its cerebellar input, whereas the prolonged saccade latency is a less-specific finding suggesting 


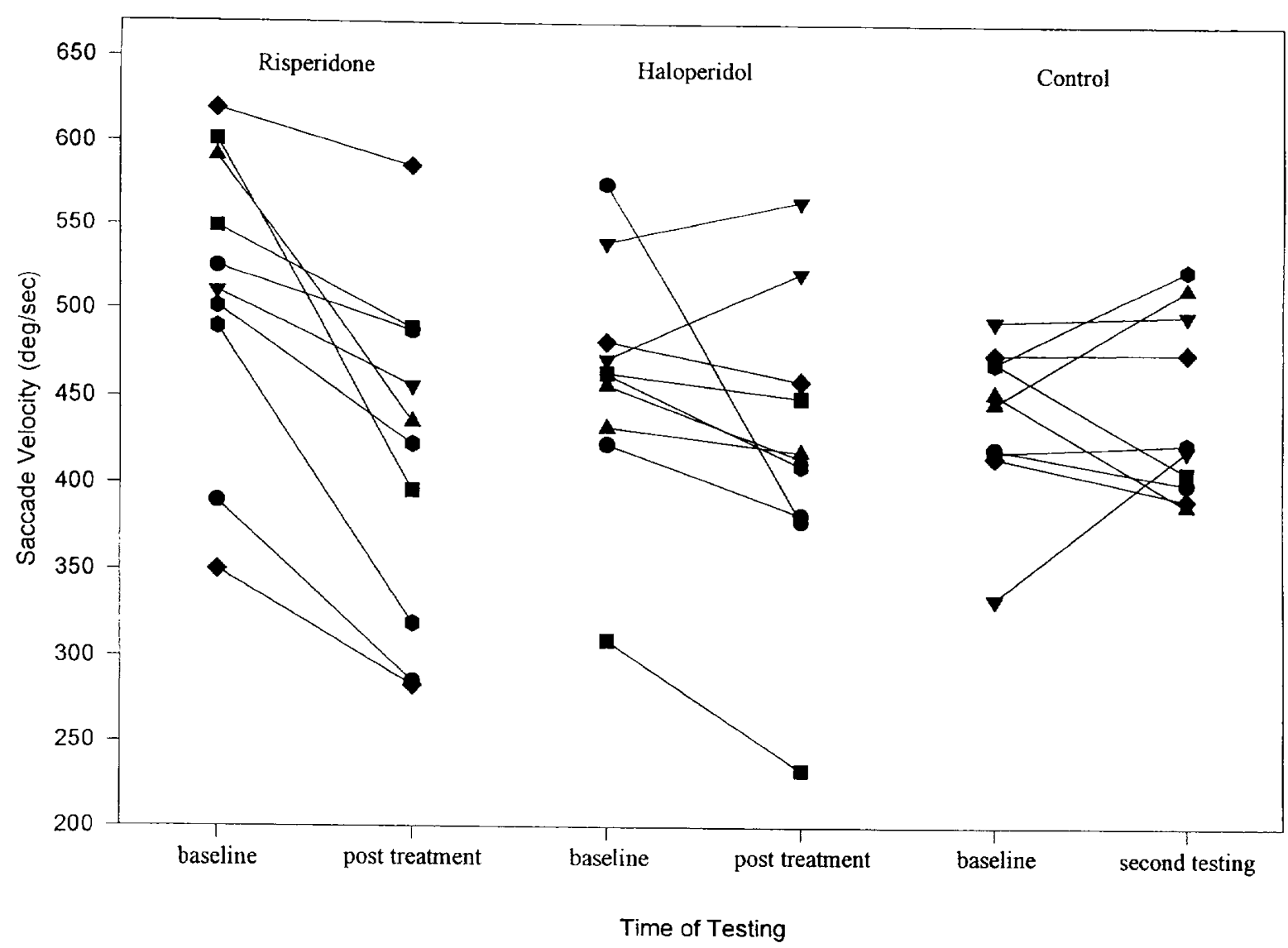

Figure 2. Individual subject data for average peak velocity of saccadic eye movements to target-steps of \pm 30 degrees of visual angle from central fixation in antipsychotic-naive schizophrenic patients before and after one month of treatment with haloperidol or risperidone, and in healthy comparison subjects.

slowed transmission of information in widely distributed visual sensorimotor systems. This pattern of generalized deficits in the saccade system is one associated with multiple CNS-active medications that reduce alertness or cause sedation, and thus it is possible that some reductions in alertness may be associated with risperidone treatment.

Mackert and Flechtner (1989), in the only published study of which we are aware investigating treatment effects on saccades in initially untreated schizophrenic patients, studied saccade latencies and reported no change after an average of 11.5 weeks of treatment with various typical neuroleptic medications. The results of the present study in haloperidol-treated patients replicate this effect in saccade latency and extend it by demonstrating that other parameters of saccade function, including peak velocity and accuracy, also appear not to be affected by the typical antipsychotic haloperidol.

The clinical relevance of our observations remain to be clarified, particularly in terms of whether risperidone-related changes in saccadic eye movements are associated with changes in the psychological alertness of patients. Investigation of linkages to patient reports of adverse effects and with neuropsychological studies of attentional functions are needed to evaluate this possibility. Should risperidone treatment be found to be associated with reduced psychological alertness, it will be important to clarify the range of severity and dose dependence of this effect. Furthermore, it will be important to determined the duration of such effects to establish whether tolerance develops over longer courses of treatment than the 1-month period examined in this study. In this context, it is important to note that haloperidol might have induced dose-dependent perturbations of saccades earlier in the course of treatment but that tolerance to such effects developed prior to our second testing 1 month after treatment initiation. Efforts to characterize better the biochemical changes resulting from risperidone that alter brainstem physiology could be of clinical relevance, as they might suggest strategies for diminishing the impact of associated adverse effects when they are troubling for patients and dose reduction is undesirable.

\section{A Possible 5-HT Mechanism}

The mechanism by which risperidone adversely impacts eye movement activity is unclear. One possibility 
is suggested by the differences in receptor-binding affinity profiles between haloperidol and risperidone (Leysen et al. 1994), particularly the powerful serotonergic effect of risperidone $\left(5-\mathrm{HT}_{2 \mathrm{~A}}\right.$ receptor antagonism). Acute administration of the serotonin precursor L-tryptophan causes drowsiness, saccadic disinhibition, and hypometric saccades (Smith and Prockop 1962; Hodge et al. 1964; Baloh et al. 1982). Fluoxetine, a potent 5-HT reuptake inhibitor, has been shown to disinhibit saccadic activity during non-rapid eye movement sleep (Schenck et al. 1992). This effect is likely to result from a potentiation of serotonergic neurons that project from the dorsal raphe nucleus and inhibit "pause" neurons, a group of brainstem neurons that play a key role in saccade control. Pause neurons provide monosynaptic inhibitory input to the pontine burst cells that drive motoneurons to initiate saccades. Inhibitory input from pause cells is dramatically reduced during saccades and resumes immediately at the end of saccades. Thus, pause cells effectively "release" burst cells so that they can initiate saccades and prevent unintended saccades at other times. The inverse off-on patterns of neurophysiological activity in burst and pause cells are precisely integrated temporally, and disturbing this synchrony disrupts the velocity characteristics of saccades (Hepp et al. 1989). In animal models, iontophoretic application of serotonin onto pause neurons markedly decreases their firing rate and disinhibits burst cells (Ashikawa et al. 1991), and lesions of serotonergic dorsal raphe projections to pause neurons markedly lowers saccade peak velocity by removing inhibitory regulation of pause cells (Kaneko and Fuchs 1991).

Alterations of serotonergic tone in other brain regions might also contribute to the observed effects of risperidone (Figure 3). The effect could be at the level of the superior colliculus (Brandao et al. 1991), cerebellar regions that project to oculomotor nuclei (Gonzalo-Ruiz et al. 1990), or via disrupted modulation of GABA-ergic projections from the caudate nucleus to the substantia nigra (Nakada et al. 1984) and from the substantia nigra to the superior colliculus (Hikosaka 1989; Lavoie and Parent 1990) (Figure 1). Perturbation of serotonergic modulation of neuronal activity in some or all of these areas may contribute to the adverse effects of risperidone on saccadic eye movements. To our knowledge, studies of serotonergic regulation of saccades in healthy human subjects have not yet been conducted. However, one recent study in healthy human subjects demonstrated that the serotonin agonist MK-212 (6-chloro-2-[1-piperazinyl]-pyrazine) alters pursuit eye movements (Friedman et al. 1994), indicating a role for serotonin in the modulation of at least some forms of eye movement activity in humans.

Other biochemical effects of risperidone also might contribute to the pharmacological effects of risperidone treatment, such as histaminergic $\left(\mathrm{H}_{1}\right)$ and $\alpha_{1}$-adreno-

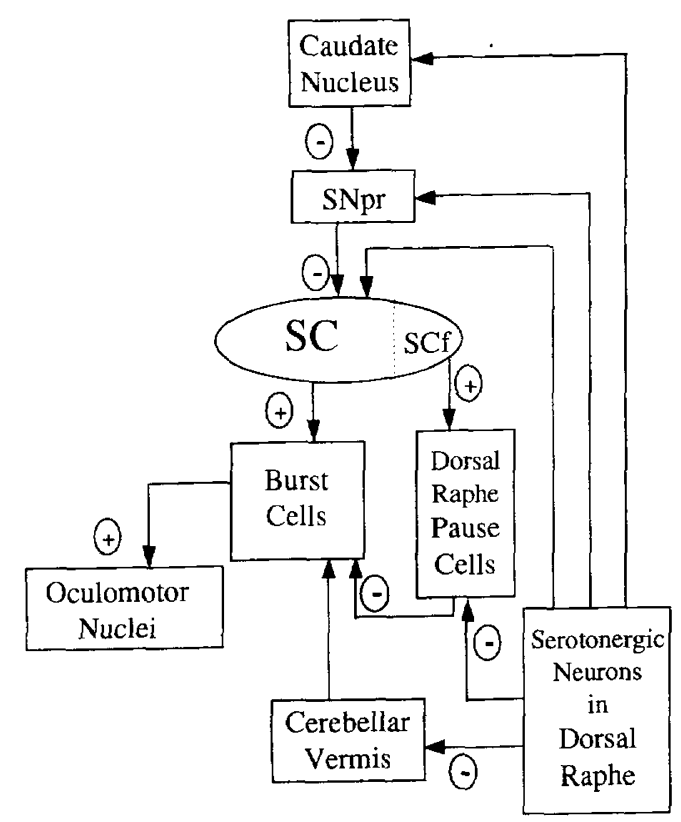

$\mathrm{SC}=$ Superior Colliculus SCf $=$ Superior Colliculus fixation zone SNpr = Substantia Nigra pars reticulata

Excitatory Input $\odot$ Inhibitory Input

Figure 3. Serotonergic innervation of subcortical brain regions known to subserve saccadic eye movements. Pathways are marked as excitatory or inhibitory when direct modulatory effects on eye movement circuitry are established.

ceptor antagonism. Dopaminergic $\left(\mathrm{D}_{2}\right)$ blockade, on its own, is not likely to be the primary cause of the observed effects of risperidone on eye movement activity. Although dopaminergic manipulations in patients with parkinsonism alter eye movement activity (Rascol et al. 1989), we observed no such adverse effects in association with haloperidol, which has a considerably greater $\mathrm{D}_{2}$ affinity than risperidone.

The observation of adverse effects of risperidone on saccadic eye movements raises an obvious methodological concern for studies of saccadic eye movements and visual information processing in schizophrenia. Based on our findings, some patients treated with risperidone and similar medications may show impairments of saccadic eye movements (and hence of visual target acquisition) because of their medication rather than (or in addition to) pathophysiological processes directly associated with their illness.

Aspects of the sampling and retesting of the subjects in the present study leave certain questions unanswered regarding the adverse effects of antipsychotic medications on saccadic eye movements. First, treatment assignment was consistent within two consecutive cohorts rather than randomly assigned, which raises some concern about the apparent differential drug effects. Although all patients were recruited in an identical fashion and displayed similar pretreatment 
eye movement performance, the possibility of some unknown cohort-specific confound cannot be fully excluded. Second, neither the magnitude of the initial acute drug effect nor the dose-response curve of the effects can be determined based on data from this study. Future neurophysiological and neurobehavioral studies of the beneficial and adverse effects of risperidone and other atypical antipsychotic medications are needed to characterize further the pharmacodynamics of this rapidly growing group of newer antipsychotic medications.

\section{ACKNOWLEDGMENTS}

We thank Ben McCurtain, Karl Drake, and James R. Carl, M.D., for assistance in developing procedures for recording and measuring eye movements, and Sally Parry and Noelle Rao for administrative assistance. This work was supported by grants from the National Institute of Mental Health (R0142969 and P50-45156).

\section{REFERENCES}

Abel LA, Levin S, Holzman PS (1992): Abnormalities of smooth pursuit and saccadic control in schizophrenia and affective disorders. Vision Res 32:1009-1014

Ammons CH, Ammons RB (1962): The Quick Test (QT): Provisional manual. Psychol Rep 11:111-161

Andreasen NC (1984a): Scale for the Assessment of Positive Symptoms (SAPS). Iowa City:

Andreasen NC (1984b): Scale for the Assessment of Negative Symptoms (SANS). Iowa City:

Ashikawa H, Furuya N, Yabe T (1991): Effects of serotonin, GABA and glycine on the activity of pause neurons during vestibular nystagmus in the cat. Acta Otolaryngol 111:999-1005

Baloh RW, Sharma S, Morkowitz H, Griffith R (1979): Effect of alcohol and marijuana on eye movements. Av Space Environ Med 50:18-23

Baloh RW, Dietz J, Spooner JW (1982): Myoclonus and ocular oscillations induced by L-tryptophan. Ann Neurol 11:95-97

Becker W (1989): Metrics. In Wurtz RH, Goldberg ME (eds), The Neurobiology of Saccadic Eye Movements. New York, Elsevier, pp 13-39

Bittencourt PRM, Wade P, Smith AT, Richens A (1981): The relationship between peak velocity of saccadic eye movements and serum benzodiazepine concentration. Br J Clin Pharmacol 12:523-533

Borison RL, Pathiraja AP, Diamond Bl, Meibach RC (1992): Risperidone: Clinical safety and efficacy in schizophrenia. Psychopharmacol Bull 28:213-218

Brandao ML, Lopez-Garcia JA, Graeff FG, Roberts MHT (1991): Electrophysiological evidence for excitatory 5- $\mathrm{HT}_{2}$ and depressant $5-\mathrm{HT}_{1 \mathrm{~A}}$ receptors on neurones of the rat midbrain tectum. Brain Res 556:259-266
Brooks BA, Fuchs AF, Finocchio D (1986): Saccadic eye movement deficits in the MPTP monkey model of Parkinson's disease. Brain Res 383:402-407

Cegalis JA, Sweeney JA, Dellis EM (1982): Refixation saccades and attention in schizophrenia. Psychiatry Res 7:189-198

Centorrino F, Baldessarini RJ, Kando JC, Frankenburg FR, Volpicelli SA, Flood JG (1994): Clozapine and metabolites: Concentrations in serum and clinical findings during treatment of chronically psychotic patients. J Clin Psychopharmacol 14:119-125

Chouinard G, Arnott W (1993): Clinical review of risperidone. Can J Psychiatry 38:S89-S95

Chouinard G, Jones B, Remington G, Bloom D, Addington D, MacEwan GW, Labelle A, Beauclair L, Arnott W (1993): A Canadian multicenter placebo-controlled study of fixed doses of risperidone and haloperidol in the treatment of chronic schizophrenic patients. J Clin Psychopharmacol 13:25-40

Clementz B, Sweeney JA (1990): Is eye movement dysfunction a biological marker for schizophrenia? A methodological review. Psychol Bull 108:77-92

Clementz BA, McDowell JE, Zisook S (1994): Saccadic system functioning among schizophrenia patients and their first-degree biological relatives. J Abnormal Psychol 103:277-287

Crawford TJ, Haeger B, Kennard C, Reveley MA, Henderson L (1995a): Saccadic abnormalities in psychotic patients. I. Neuroleptic-free psychotic patients. Psychol Med 25:461-471

Crawford TJ, Haeger B, Kennard C, Reveley MA, Henderson L (1995b): Saccadic abnormalities in psychotic patients. II. The role of neuroleptic treatment. Psychol Med 25:473-483

Czobor P, Valavka J (1993): Quantitative electroencephalogram examination of effects of risperidone in schizophrenic patients. J Clin Psychopharmacol 13:332-342

Fischer B (1987): The preparation of visually guided saccades. Rev Physiol Biochem Pharmacol 106:1-35

Fox PT, Fox JM, Raichle ME, Burde RM (1985): The role of cerebral cortex in the generation of voluntary saccades: A positron emission tomographic study. J Neurophysiol 54:348-369

Friedman L, Jesberger JA, Meltzer HY (1991): Effect of typical antipsychotic medications and clozapine on smooth pursuit performance in patients with schizophrenia. Psychiatry Res 41:25-36

Friedman L, Jesberger JA, Meltzer HY (1994): The effect of apomorphine, MK-212 (6-chloro-2-[piperazinyl]-pyrazine) and placebo on smooth pursuit gain and corrective saccades in normal subjects. Neuropsychopharmacology 11:49-62

Friedman L, Jesberger JA, Siever LJ, Thompson P, Mohs R, Meltzer HY (1995): Smooth pursuit performance in patients with affective disorders or schizophrenia and normal controls: Analysis with specific oculomotor measures, RMS error and qualitative ratings. Psychol Med 25:387-403

Fukushima J, Morita N, Fukushima AK, Chiba T, Tanaka S, Yamashita I (1990): Voluntary control of saccadic eye 
movements in patients with schizophrenic and affective disorders. J Psychiatry Res 24:9-24

Gao F, Marshall RW, Vickers MD (1991): Effect of low concentrations of nitrous oxide and isoflurane on peak velocity of saccadic eye movements. $\mathrm{Br}$ J Anaesthesia $66: 179-184$

Glue P, White E, Wilson S, Ball DM, Nutt DJ (1991): Pharmacology of saccadic eye movements in man: 2 . Effects of the alpha 2-adrenoceptor ligands idazoxan and clonidine. Psychopharmacology 105:368-373

Godaux E, Cheron G, Mettens P (1990): Ketamine induces failure of the oculomotor neural integrator in the cat. Neurosci Lett 116:162-167

Goldman-Rakic PS, Bates JF, Chafee MV (1992): The prefrontal cortex and internally generated motor acts. Cur Opin Neurobiol 2:830-835

Gonzalo-Ruiz A, Leichnetz GR, Hardy SGP (1990): Projections of the medial cerebellar nucleus to oculomotorrelated midbrain areas in the rat: An anterograde and retrograde HRP study. J Comp Neurol 296:427-436

Heinrich K, Kleieser E, Lehmann E, Kinzler E, Hruschka H (1994): Risperidone versus clozapine in the treatment of schizophrenic patients with acute symptoms: A double blind, randomized trial. Prog Neuro-Psychopharmacol Biol Psychiatry 18:129-137

Hepp K, Henn V, Vilis T, Cohen B (1989): Brainstem regions related to saccade generation. In Wurtz RH, Goldberg ME (eds), The Neurobiology of Eye Movements. New York, Elsevier, pp 105-212

Hikosaka O (1989): Role of basal ganglia in saccades. Rev Neurol 145:580-586

Hodge JV, Oates JA, Sjoerdsma A (1964): Reduction of the central effects of tryptophan by a decarboxylase inhibitor. Clin Pharmacol Ther 5:149-155

Holzman PS, Proctor LR, Levy DL, Yasillo NJ, Meltzer HY, Hirt SW (1974): Eye-tracking dysfunctions in schizophrenic patients and their relatives. Arch Gen Psychiatry 31:143-151

Hommer DW, Matsuo VM, Wolkowitz O, Chrousos G, Greenblatt DJ, Weingartner H, Paul SM (1986): Benzodiazepine sensitivity in normal human subjects. Arch Gen Psychiatry 43:542-551

Hoyberg OJ, Fensbo C, Remvig J, Lingjaerde O, SlothNielsen M, Salvesen I (1993): Risperidone versus perphenazine in the treatment of chronic schizophrenic patients with acute exacerbations. Acta Psychiatr Scand 88:395-402

Janssen PAJ, Awouters FHL (1994): Is it possible to predict the clinical effects of neuroleptics from animal data? Drug Res 44:269-277

Jurgens R, Becker JW, Kornhuber HH (1981): Natural and drug-induced variations of velocity and duration of human saccadic eye movements: Evidence for a control of the neural pulse generator by local feedback. Biol Cybern 39:87-96

Kaneko CRS, Fuchs AF (1991): Saccadic eye movement deficits following ibotenic acid lesions of the nuclei raphe interpositus and prepositus hypoglossi in monkey. Acta Otolaryngol 481:213-215
Katoh Z (1988): Slowing effects of alcohol on voluntary eye movements. Avia Space Environ Med 59:606-610

Keller EL (1989): The cerebellum. In Wurtz RH, Goldberg ME (eds), The Neurobiology of Saccadic Eye Movements. New York, Elsevier, pp. 391-411

King DJ, Lynch G, Mannion MF, Montgomery RC, Tiplady B, Yisak W (1995): The effects of remoxipride and chlorpromazine on eye movements and psychomotor performance in healthy volunteers. J Psychopharmacol 9:143-149

Konrad HR, Rea C, Olin B, Colliver J (1989): Simultaneous auditory stimuli shorten saccade latencies. Laryngoscope 99:1230-1232

Kroboth PD, Sweeney JA, Bauer KS, Corey SE, Wright CE, Tullock WC, Watkins WD, Folan MM (1995): Saccadic eye movements: Use in a study of tolerance to alprazolam. Clin Pharmacol 57:145

Lavoie B, Parent A (1990): Immunohistochemical study of the serotonergic innervation of the basal ganglia in the squirrel monkey. J Comp Neurol 299:1-16

Levy DL, Holzman PS, Matthysse S, Mendell NR (1994): Eye tracking and schizophrenia-A selective review. Schizophren Bull 20:47-62

Leysen JE, Janssen PMF, Megens AAHP, Schotte A (1994): Risperidone: A novel antipsychotic with balanced serotonin-dopamine antagonism, receptor occupancy profile, and pharmacologic activity. J Clin Psychiatry 55:5-12

Lieberman JA, Safferman AZ (1992): Clinical profile of clozapine: Adverse reactions and agranulocytosis. Psychiatric Q 63:51-70

Litman RE, Hommer DW, Radant A, Clem T, Pickar D (1994): Quantitative effects of typical and atypical neuroleptics on smooth pursuit eye tracking in schizophrenia. Schizophr Res 12:107-120

Mackert A, Flechtner M (1989): Saccadic reaction times in acute and remitted schizophrenics. Eur Arch Psychiatry Neurol Sci 239:33-38

Marder SR, Meibach RC (1994): Risperidone in the treatment of schizophrenia. Am J Psychiatry 151:825-835

Mather JA, Putchat C (1982): Motor control of schizophrenics-I. Oculomotor control of schizophrenics: A deficit in sensory processing, not strictly in motor control. J Psychiatr Res 17:343-360

McEvoy JP, Hogarty GE, Steingard S (1991): Optimal dose of neuroleptic in acute schizophrenia: A controlled study of the neuroleptic threshold and higher haloperidol dose. Arch Gen Psychiatry 48:739-745

Mesotten F, Suy E, Pietquin M, Burton P, Heylen S, Gelders $Y$ (1989): Therapeutic effect and safety of increasing doses of risperidone ( $R$ 64766) in psychotic patients. Psychopharmacology 99:445-449

Moser A, Kompf D, Arolt V, Resch T (1990): Quantitative analysis of eye movements in schizophrenia. Neuroophthalmology 10:73-80

Nakada MT, Weiczorek CM, Rainbow TC (1984): Localization and characterization by quantitative autoradiography of $\left[{ }^{125}\right.$ I] LSD binding sites in rat brain. Neurosci Lett 49:13-18

Nyberg S, Farde L, Eriksson L, Halldin C, Eriksson B (1993): $5-\mathrm{HT}_{2}$ and $\mathrm{D}_{2}$ dopamine receptor occupancy in the living human brain. Psychopharmacology 110:265-272 
Oepen G, Thoden U, Warmke C (1990): Association of tardive dyskinesia with increased frequency of eye movement disturbances in chronic schizophrenic patients. Eur Arch Psychiatry Neuro Sci 239:241-245

Overall JE, Gorham DR (1962): The Brief Psychiatric Rating Scale. Psychol Rep 10:799-812

Owens DGC (1994): Extrapyramidal side effects and tolerability of risperidone. A review. J Clin Psychiatry 55:29-35

Pyykko I, Padoan S, Schalen L, Lyttkens L, Magnusson M, Henriksson NG (1985): The effects of TTS-scopolamine, dimenhydrinate, lidocaine, and tocainide on motion sickness, vertigo, and nystagmus. Aerospace Med Assoc 56:777-782

Raczkowski D, Kalat JW (1974): Reliability and validity of some handedness questionnaire items. Neuropsychologia 12:43-47

Rascol O, Clanet M, Montastruc JL, Simonetta M, SoulierEsteve MJ, Doyon B, Rascol A (1989): Abnormal ocular movements in Parkinson's disease: Evidence for involvement of dopaminergic systems. Brain 112:1193-1214

Rothenberg S, Schottenfeld S, Gross K, Selkoe D (1980): Specific oculomotor deficit after acute methadone I. Saccadic eye movements. Psychopharmacology 67:221-227

Roy-Byrne PP, Cowley DS, Radant A, Hommer D, Greenblatt DJ (1993): Benzodiazepine pharmacodynamics: Utility of eye movement measures. Psychopharmacology 110:85-91

Sawaguchi T, Goldman-Rakic PS (1991): $\mathrm{D}_{1}$ dopamine receptors in prefrontal cortex: Involvement in working memory. Science 251:947-950

Sawaguchi T, Matsumura M, Kubota K (1989): Depth distribution of neuronal activity related to a visual reaction time task in the monkey prefrontal cortex. J Neurophysiol 61:435-446

Schalen L, Pyykko I, Korttila K, Magnusson M, Enbom H (1988): Effects of intravenously given barbiturate and diazepam on eye motor performance in man. Adv OtoRhino Laryngol 42:260-264

Schenck CH, Mahowald MW, Kim SW, O'Connor KA, Hurwitz TD (1992): Prominent eye movements during NREM sleep and REM sleep behavior disorder associated with fluoxetine treatment of depression and obsessive-compulsive disorder. Sleep 15:226-235

Schooler NR (1994): Negative symptoms in schizophrenia: Assessment of the effect of risperidone. J Clin Psychiatry 55:22-28
Schultz W, Romo R, Scarnati E, Sundstrom E, Jonsson G, Studer A (1989): Saccadic reaction times, eye-arm coordination and spontaneous eye movements in normal and MPTP-treated monkeys. Exp Brain Res 78:253-267

Smith B, Prockop DJ (1962): Central-nervous-system effects of ingestions of L-tryptophan by normal subjects. N Engl J Med 267:1338-1341

Spitzer RL, Williams JBW, Gibbons M, First M (1987): Structured clinical interview for DSM-III-R (SCID), New York, New York State Psychiatric Institute

Sumiyoshi T, Kido H, Sakamoto H, Urasaki K, Suzuki K, Yamaguchi N, Mori H, Shiba K, Yokogawa K (1994): In vivo dopamine- $\mathrm{D}_{2}$ and serotonin-5- $\mathrm{HT}_{2}$ receptor binding study of risperidone and haloperidol. Pharmacol Biochem Behav 47:553-557

Sweeney JA, Clementz BA, Haas GL, Escobar MD, Drake K, Frances AJ (1994a): Eye tracking dysfunction in schizophrenia: Characterization of component eye movement abnormalities, diagnostic specificity, and the role of attention. J Abnormal Psychol 103:222-230

Sweeney JA, Haas GL, Li S, Weiden PJ (1994b): Selective effects of antipsychotic medication on eye-tracking performance in schizophrenia. Psychiatry Res 54:185-198

Sweeney JA, Mintun MA, Kwee S, Wiseman MB, Brown DL, Rosenberg DR, Carl JR (1996): A positron emission tomography study of voluntary saccadic eye movements and spatial working memory. J Neurophysiol 75:454-468

Tedeschi G, Casucci G, Allocca S, Riva R, Di Costanzo A, Quattrone A, Baruzzi A, Bonavita V (1989): Computer analysis of saccadic eye movements: Assessment of two different carbamazepine formulations. Eur J Clin Pharmacol 37:513-516

Tedeschi G, Casucci G, Di Costanzo AD, Bonavita V (1992): Acute effect of flunarizine on saccadic eye movements. Acta Neurologica 14:326-332

Van Putten T, Marder S, Mintz J (1990): A controlled dose comparison of haloperidol in newly admitted schizophrenic patients. Arch Gen Psychiatry 47:754-758

Waitzman DM, Ma TP, Otpican LM, Wurtz RH (1991): Superior colliculus neurons mediate the dynamic characteristics of saccades. J Neurophysiol 66:1716-1737

Yee RD, Balogh RW, Marder SR, Levy DL, Sakala SM, Honrubia V (1987): Eye movements in schizophrenia. Invest Ophthalmol Vis Sci 28:366-374 